\title{
A INTELIGÊNCIA EMPRESARIAL E A BIOLOGIA DO CONHECER: uma análise exploratório-qualitativa do setor de pequenas e médias empresas de consultoria de Belo Horizonte
} THE BUSINESS INTELLIGENCE AND THE BIOLOGY OF KNOWLEDGE: an exploratory-qualitative analysis of small and medium size advertising companies of Belo Horizonte

Frederico Cesar Mafra Pereira - fmafra@eci.ufmg.br / fmafra@acad.unibh.br Mestre em Ciência da Informação pela Escola de Ciência da Informação / UFMG - Brasil

Mônica Erichsen Nassif Borges - mnassif@eci.ufmg.br Doutora em Ciência da Informação pela Escola de Ciência da Informação / UFMG - Brasil. Professora do Departamento de Gestão da Informação e do Conhecimento da Escola de Ciência da Informação / UFMG - Brasil

\section{Resumo}

Comente este artigo no blog Ebibli = http://encontros-bibli-blog.blogspot.com/

Este artigo busca contribuir para a ampliação dos estudos sobre Inteligência Empresarial e sua relação com o enfoque cognitivo da Biologia do Conhecer, a partir da observação de empresas de consultoria de pequeno e médio porte, tendo como referencial teórico a abordagem cognitiva da Biologia do Conhecer, de Maturana, utilizado nos estudos de Borges em sua tese de doutorado.

Palavras-chave: Inteligência Empresarial. Informação. Conhecimento. Pequenas e Médias Empresas. Consultoria Empresarial. Biologia do Conhecer.

\section{INTRODUÇÃO}

Este artigo aborda o tema da inteligência empresarial, tendo como referencial teórico a abordagem cognitiva da Biologia do Conhecer, de Maturana (1997), trabalhada por Borges (2002) junto a empresas de pequeno e médio porte $(\mathrm{PME})^{1}$ de diferentes segmentos. Trata-se de um estudo preliminar sobre o tema, de caráter exploratório qualitativo, através da realização de três entrevistas semi-estruturadas junto a consultores de PME de consultoria de Belo Horizonte, de diferentes áreas de atuação. Os objetivos do trabalho foram, primeiramente, levantar, junto aos consultores, dados sobre suas histórias de vida e de suas empresas, mercado de atuação profissional e, principalmente, sobre as relações que estabelecem no seu dia-a-dia de trabalho, tanto pessoais quanto profissionais, e como estas auxiliam no processo de tomada de decisão em suas empresas. Estes aspectos ajudam no entendimento de como os consultores trabalham o tema da inteligência empresarial em suas

\footnotetext{
${ }^{1}$ Neste artigo, serão utilizadas as siglas PME, MPE e MPME em substituição, respectivamente, às expressões "Pequenas e Médias Empresas", "Micro e Pequenas Empresas" e "Micro, Pequenas e Médias Empresas".
} 
empresas, e como suas relações pessoais e profissionais os ajudam a definirem o que é informação relevante para seus negócios, e que decisões podem ser tomadas com estas informações. Outro objetivo do trabalho foi levantar dados sobre um segmento de negócios específico, que permitisse a comparação dos resultados alcançados com o estudo de Borges (2002), sendo adotada a mesma metodologia de pesquisa desta última para este trabalho.

Além desta introdução, o artigo é estruturado em seis partes. Começa com uma breve contextualização do mercado de PME e de consultoria no Brasil, e a justificativa para a escolha deste público para o trabalho. Num segundo momento, discorre sobre o conceito e a atividade de inteligência empresarial, e sua importância para a gestão de empresas. Em seguida, apresenta a relação entre a ciência da informação e a abordagem cognitiva da Biologia do Conhecer, os conceitos de informação e conhecimento utilizados, e o conceito de redes de interações e relações para explicar como estas redes influenciam as condutas dos indivíduos no meio no qual estão inseridos. Depois, apresenta a metodologia de pesquisa utilizada no trabalho e perfis dos entrevistados, seguida dos resultados da pesquisa e a relação destes com a abordagem da Biologia do Conhecer e com os resultados obtidos por Borges (2002). Por último, apresenta as considerações finais sobre o trabalho.

\section{AS PME E A ATIVIDADE DE CONSULTORIA EMPRESARIAL NO BRASIL - UMA BREVE CONTEXTUALIZAÇÃO}

No Brasil, as PME apresentam características muito particulares, quando comparadas às grandes organizações, em função da história da industrialização brasileira, dos investimentos governamentais e da trajetória política e econômica do país. Pertencem normalmente a um indivíduo, a grupos familiares ou a pequenas sociedades comerciais. Além disso, possuem um tipo de administração pouco especializada e são muito ligadas às características e personalidade de seus proprietários, como talento, sensibilidade, vontade de realização, dentre outras (CARMO e PONTES, 1999, MARTIN, 1989).

As PME se constituem em importantes atores do próprio desenvolvimento do país. De acordo com dados do IBGE, de 2002, o total de empresas em atividade no Brasil alcançava 4.918.370 unidades, nos setores da indústria, construção, comércio e serviços, sendo que o conjunto das MPME alcançava 99,7\% do total. A geração de empregos nas empresas formais alcançava o total de 27.561 .924 ocupações, representando $42 \%$ de toda a população economicamente ativa no meio urbano. Deste total, $67 \%$ estavam empregadas em MPME 
(18.457.179 pessoas). Entretanto, conforme Terra e Kruglianskas (2003), o que pode ser verificado, com muita freqüência, são estudos voltados ao entendimento da realidade das grandes empresas, "que muitas vezes utilizam linguagens distantes das utilizadas..., principalmente nas (empresas) de pequeno porte".

$\mathrm{Na}$ literatura sobre inteligência empresarial em PME, observa-se uma lacuna, segundo Borges (2002), pois grande parte dos trabalhos é realizada a partir de grandes organizações, cuja premissa é a de que o ambiente externo de negócios é que determina o comportamento organizacional de qualquer empresa. Porém, as PME apresentam uma dinâmica organizacional distinta das empresas de grande porte, com particularidades específicas, e que se interagem num "meio" também de características específicas. Borges (2003) aponta, como uma de suas principais características, a "personalização".

\begin{abstract}
A personalização diz respeito à relação de proximidade entre o empresário e o seu negócio. O pequeno empresário é aquele indivíduo que concebe o seu negócio e o gerencia. Isso faz com que ele seja o elemento determinador da forma de gerenciar a empresa, de estabelecer contatos e de definir os focos de atenção sobre o ambiente de negócios. (BORGES, 2003).
\end{abstract}

Para Oliveira e Bertucci (2003) "as PME podem ser vistas como extensão da personalidade de seus proprietários, e por isso eles têm um papel fundamental no clima organizacional e nos processos decisórios". E segundo Chér (1990), o empresário de PME é capaz de perceber, com facilidade, sinais de mudança no seu ambiente de negócios. Borges (2003) ainda destaca que, apesar da literatura sobre PME abordar a característica da personalização, os perfis dos gestores e a forma como observam o ambiente de negócios não são muito discutidos no contexto da inteligência empresarial.

Com relação à atividade de consultoria empresarial, esta é um dos segmentos de prestação de serviços que mais têm crescido no mundo, segundo Oliveira (2003), principalmente pela possibilidade de maior rapidez na evolução dos conhecimentos adquiridos pelos profissionais e pela percepção de um crescimento maior em relação a outros negócios, especialmente os segmentos da indústria e do comércio. Outras tendências de crescimento, apontadas por Oliveira (2003), são: 1) Busca das empresas para consolidação de suas vantagens competitivas; 2) Necessidade de questionamento progressivo das empresas com relação às suas realidades, visando a um processo de melhoria contínua sustentada; 3 ) Conseqüência dos processos de terceirização das empresas; 4) Aumento do número de professores e universidades que prestam serviços de consultoria, dentre outros.

Segundo Donadone (2001) os anos 80 marcam o início de importantes transformações no mercado de consultoria, de forma geral. O crescimento e maior vislumbre do setor, 
associados a mudanças nas formas de atuação, de relacionamento com as empresas contratantes e a inserção de divulgação e venda de pacotes gerenciais, formataram características que serviram de suporte para a configuração e importância que o setor adquiriria nos anos $90^{2}$. Outro componente foi à questão da Tecnologia da Informação (TI), com a difusão dos computadores pessoais nas empresas, nos anos 80, e a introdução de "pacotes de gerenciamento" baseados em TI. Nos anos 90, o setor de consultoria ganhou destaque nos meios gerenciais e empresariais devido aos processos de reengenharia e às mudanças organizacionais associadas aos redesenhos organizacionais, ao downsizing ${ }^{3}$, ao surgimento dos "gurus empresariais", às empresas especializadas em estratégia organizacional, tecnologia da informação e teorias desenvolvidas e disponibilizadas através de "pacotes gerenciais", contemplando as formas de interação entre empresas de consultoria, imprensa de negócios e setores acadêmicos.

Com relação ao mercado de consultoria empresarial no Brasil, este vem crescendo de forma acelerada, principalmente a partir de meados da década de 60 , devido ao crescimento do parque industrial do país, à penetração crescente de multinacionais americanas e à necessidade de conhecimento atualizado das técnicas e metodologias de gestão empresarial para fazer frente ao novo contexto de concorrência entre as empresas, resultante do processo de globalização econômica. No início dos anos 90, este crescimento se intensificou, com a abertura de mercado e maior competitividade nos tempos do Governo Collor. Segundo Micheletti (2002) o mercado de consultoria no Brasil teve três fases. A primeira ocorreu com a privatização das estatais, onde todas as companhias resolveram ir a busca de competitividade. A segunda veio com o conceito de qualidade total e com a implantação da ISO 9000 no Brasil. A terceira e última fase é mais recente e compreende a última década (1990), onde os sistemas de gestão viraram febre no mundo empresarial.

Embora não haja dúvidas de que o mercado de consultoria no Brasil está crescendo, a identificação do seu tamanho é problemática, pois as empresas têm desinteresse em divulgar seus números. Donadone (2001) menciona a falta de estatísticas sobre o setor no Brasil, e se quando se avalia o mercado de PME de consultoria, este problema se torna ainda mais crítico.

\footnotetext{
${ }^{2}$ Segundo Donadone (2001), no período destacava-se a implementação de ferramentas gerenciais inspiradas nas idéias de gestão empresarial japonesa. Com o decorrer da década, os espaços de atuação das consultorias ganharam novas dimensões, mudando o enfoque de características funcionais das práticas japonesas para pacotes gerenciais e que visavam contemplar os diversos setores presentes nas empresas.

3 Segundo Chiavenato (2003), Downsizing (ou "enxugamento") "é a redução de níveis hierárquicos de uma organização para manter o essencial e a aproximação da base em relação à cúpula. Geralmente, é acompanhado de descentralização". Este processo, portanto, promove redução de níveis hierárquicos e enxugamento organizacional para reduzir as operações ao essencial (core business) do negócio e transferir o acidental para terceiros que saibam fazê-lo melhor e mais barato (terceirização).
} 


\section{INTELIGÊNCIA EMPRESARIAL - CONCEITOS E CARACTERÍSTICAS DA ATIVIDADE}

As organizações, de forma geral, têm sofrido transformações intensas em suas estruturas, processos internos e em sua própria dinâmica, devido às mudanças constantes em seus ambientes de negócios. Segundo Paim e Barbosa (2003) essas mudanças ocorrem no ambiente externo dessas organizações, e são resultados da interação entre as inovações tecnológicas e as transformações sócio-econômicas pelas quais as sociedades vêm passando. Diante desse cenário, as empresas e seus administradores têm se esforçado no sentido de acompanharem essas mudanças, interpretá-las e compreenderem suas implicações para seus negócios, além de buscarem constante atualização sobre estes fatores de mudança e utilizarem as informações obtidas nos processos de tomada de decisões. Entretanto, o caminho entre a informação necessária e sua efetiva utilização pelos administradores em suas estratégias e ações é complexo, como destaca Barbosa (1997).

Neste sentido, é importante que as empresas implementem ações no sentido de monitorarem o seu ambiente de negócios. Um dos precursores deste tema foi Aguilar (1967), que definiu o termo monitoramento ambiental ${ }^{4}$ como

... a busca de informações sobre eventos e relacionamentos no ambiente externo de uma empresa, o conhecimento dos quais irá auxiliar os executivos principais na tarefa de definir a futura linha de ação da empresa. (AGUILAR, 1967) ${ }^{5}$

Muitos conceitos são associados ao de monitoração ambiental, dentre eles o de inteligência empresarial. Para Barbosa (1997) estes dois conceitos são, em muitos contextos, considerados equivalentes. Com relação ao conceito de inteligência empresarial, especificamente, este diz respeito, segundo Barbosa (2002),

... ao estudo da natureza da concorrência sob uma perspectiva mais ampla. Esta procura incorporar, em sua análise, fenômenos econômicos, sociais e políticos que possam ser de importância para o sucesso da empresa. (BARBOSA, 2002)

Para Borges (2002), inteligência empresarial refere-se

... a todo conjunto de atividades voltadas para a obtenção, para o processamento, a análise e a disseminação de informação acerca do ambiente de negócios de organizações de produção, com o objetivo de dar suporte à tomada de decisão e à definição estratégica. (BORGES, 2002)

\footnotetext{
4 O termo "monitoração" vem do inglês "scanning", que significa "escrutinar ponto por ponto" (AGUILAR, 1967). Ainda segundo Aguilar (1967,), scanning envolve uma exposição a uma informação e a percepção sobre a mesma. (N.T.)

${ }^{5}$ Tradução de Barbosa (1997).
} 
Segundo Barbosa (2002) a inteligência empresarial constitui-se em um elemento central para o processo de desenvolvimento do conhecimento organizacional, tanto para a formação de sentido (sensemaking) a respeito do ambiente externo de negócios, para a criação de conhecimento (aprendizagem organizacional) ou para auxiliar no processo de tomada de decisão (CHOO, 2003). A aplicabilidade dos conceitos sobre inteligência empresarial não se restringe, apenas, às grandes organizações. Como seu uso adequado é, nos dias de hoje, fator de competitividade para qualquer empresa, de qualquer porte, e em qualquer setor do mercado, é importante que estudos sejam desenvolvidos também focando a realidade, principalmente, das MPME.

Ainda segundo Aguilar (1967), as informações necessárias às organizações, para um adequado monitoramento do seu ambiente de negócios, são sempre informações externas a estas, advindas, quase sempre, de fontes externas. Entretanto, algumas informações externas do ambiente de negócios das organizações também são advindas de fontes internas. Como exemplo, pode-se citar o caso de um gerente ou administrador de uma empresa que busca informações e opiniões acerca do ambiente de negócios de sua organização junto a colegas de trabalho: neste caso, as informações obtidas através dos colegas de trabalho (fontes internas) podem revelar aspectos do ambiente externo de negócios, sendo, estas, informações externas advindas de fontes internas. Portanto, para um adequado trabalho de monitoramento ambiental é necessária a identificação e o uso não só de fontes externas, mas também de fontes internas para a busca de informações sobre o ambiente de negócios de uma organização. Neste sentido, é importante, na atividade de inteligência empresarial, que se busque compreender como se dá as relações pessoais e profissionais dos funcionários e executivos da empresa no dia-a-dia de suas atividades, pois estas relações podem elucidar e explicar que informações são consideradas relevantes para a tomada de decisão e/ou auxiliar no processo de aprendizagem organizacional.

\section{A RELAÇÃO ENTRE A CIÊNCIA DA INFORMAÇÃO E A ABORDAGEM COGNITIVA DA BIOLOGIA DO CONHECER - CONCEITOS DE INFORMAÇÃO, CONHECIMENTO E REDES DE INTERAÇÕES E RELAÇÕES}

A partir do final dos anos 70 um grande número de pesquisadores da ciência da informação convenceu-se de que um caminho promissor para a área seria abordá-la sob um enfoque cognitivo (VAKKARI, 1994). Neste sentido, alguns estudos sobre o relacionamento 
entre a ciência da informação e as ciências cognitivas visavam o entendimento sobre o comportamento de usuários de sistemas, produtos e serviços de informação, ambientes organizacionais para a estruturação de sistemas de informação, implantação de atividades de gestão da informação, de inteligência competitiva, dentre outros. Estes estudos abordavam a questão da informação como elemento gerador de conhecimento, e que o conhecimento se dava quando a informação era percebida e aceita, sendo toda alteração provocada no estoque mental de saber do indivíduo, através da interação com estruturas de informação ${ }^{6}$.

Maturana e Varella (1984) apresentaram, então, a abordagem da Biologia do Conhecer, propondo uma discussão sobre a natureza do conhecer, que parte da premissa de que os seres vivos são sistemas determinados por sua estrutura, numa condição de complementaridade estrutural entre sistema e meio. Para eles, o meio pode somente desencadear uma mudança estrutural no organismo, mas não sob a idéia de que a informação é determinante do conhecimento, e este do comportamento, mas sim de que o meio pode ou não desencadear comportamentos, sendo que esta dinâmica ocorre tanto do meio para o organismo, quanto do organismo para o meio. Nesta perspectiva, somente é informação a "perturbação do meio 'aceita' pela estrutura do indivíduo" (BORGES, 2003). O que vai definir a aceitação de uma perturbação como informação é a estrutura biológica do "usuário de informação", considerando a sua pré-disposição emocional em aceitar tal perturbação, sua história de vida e os domínios de ação por onde transita. O conhecimento é "conduta adequada e ação efetiva em um contexto relacional no qual cada comportamento é um ato cognitivo", e cognição é "uma ação que depende de interação congruente" (BORGES, 2003). Borges (2003) afirma que os indivíduos têm histórias únicas, interagem de formas diferentes com o meio e, por isso, conhecem e aprendem de formas diferentes.

Ao se adotar os conceitos de informação e conhecimento sob a ótica da Biologia do Conhecer, deve-se considerar os "usuários de informação" como seres humanos individuais e sociais, que possuem suas experiências individuais determinadas por sua estrutura biológica, mas que, ao mesmo tempo, vivem em interação constante com outros indivíduos, ou em diferentes "domínios de ação" (empresa, família, lazer, amigos, etc.). Desta forma, os indivíduos fazem parte de diferentes redes de relações e interações estabelecidas em cada domínio pelos quais transitam, e estas redes influenciam suas condutas no meio ("ato de conhecer"), sua linguagem e suas pré-disposições de aceitar ou não determinada "perturbação" (informação).

\footnotetext{
${ }^{6}$ Ver também Belkin (1990) e Brookes (1980), citados na bibliografia.
} 
O conceito de "redes de relações e interações" substitui, na Biologia do Conhecer, o significado de "fontes de informação" utilizado pelas teorias cognitivas tradicionais. De acordo com Borges (2004), o termo "fontes de informação" caracteriza uma situação "externa" ao indivíduo, determinando um "lócus" onde a "informação" pode estar disponível para o uso e tomada de decisões. Já o termo "redes de relações e interações" corresponde às formas do indivíduo interagir com o seu meio e com outros indivíduos, permitindo que ele seja ou não influenciado por "perturbações" que modifiquem sua conduta no meio.

\section{Metodologia de PeSquisa JUNTO A CONSUltores DE PME DE CONSULTORIA DE BELO HORIZONTE}

Para este trabalho, foram realizadas 03 (três) entrevistas de caráter exploratório / qualitativo, junto a consultores que atuam no mercado de consultoria de Belo Horizonte (MG), todos proprietários de empresas de pequeno e médio porte. Um dos consultores entrevistados trabalha como profissional autônomo, é do sexo masculino, tem 32 anos, graduado em Economia, com pós-graduação em Marketing e mestrado em Administração. Sua atuação se dá nas áreas de Marketing e de Pesquisa de Mercado para pequenas empresas, já atuando neste ramo há 9 anos. O segundo entrevistado é sócio-proprietário de uma pequena empresa de consultoria (16 funcionários), com atuação nas áreas de Planejamento e Pesquisa de Mercado. Trabalha há mais de 20 anos neste segmento, tem 62 anos, é do sexo masculino, graduado em Sociologia, com pós-graduação em Estatística. O terceiro entrevistado trabalha há 17 anos no segmento de consultoria, tendo sido fundador de uma cooperativa de consultores, hoje de médio porte (com, aproximadamente, 80 associados), da qual é, atualmente, o diretor geral. É também do sexo masculino, tem 58 anos, graduado em Veterinária, com pós-graduação em Administração Rural e mestrado em Sociologia. Sua atuação se dá nas áreas de Agronegócios, Planejamento Rural, Projetos em Educação, e Assessoria a Prefeituras, ONG's e Entidades de Defesa Ambiental.

O trabalho foi desenvolvido com base na metodologia adotada por Borges (2002), que se utilizou da técnica de pesquisa qualitativa de caráter exploratório, e que é justificada pela autora como

... uma atividade que coloca o observador no mundo. Consiste em um conjunto de práticas interpretativas que tornam o mundo visível e o representam através de entrevistas, conversas, fotografias e recordações, envolvendo uma abordagem interpretativa e naturalista do mesmo. (BORGES, 2002) 
Cabe ressaltar que o método qualitativo exploratório não deve ser completamente desestruturado, mas deve conter sessões que levem a um objetivo específico. Portanto, a entrevista foi escolhida como forma de coleta de dados da pesquisa, e seguiu um roteiro de perguntas semi-estruturado em três blocos. O primeiro bloco conteve perguntas sobre o respondente, sua história de vida familiar e profissional, suas relações no dia-a-dia e suas leituras prediletas. O segundo bloco conteve perguntas sobre a empresa do respondente, aspectos referentes à sua criação, ambiente no qual atua e percepção sobre o mercado. $\mathrm{O}$ terceiro bloco utilizou a técnica de "incidente crítico", que teve como objetivo permitir que o entrevistado descrevesse uma situação ocorrida no ambiente da empresa (sem distinção entre ambiente interno ou externo) e que tivesse uma relação direta com ele, que o tenha influenciado a tomar uma decisão importante, permitindo observar se o evento foi uma informação, tal como considerada nos estudos sobre inteligência empresarial ou com base na Biologia do Conhecer ${ }^{8}$.

Como apontado na introdução, os aspectos investigados auxiliaram no entendimento de como os consultores trabalham o tema da inteligência empresarial em suas empresas, e como suas relações pessoais e profissionais os ajudam a definirem o que é informação relevante para seus negócios, e que decisões podem ser tomadas com estas informações. Portanto, o roteiro conteve perguntas relacionadas à formação do entrevistado, sua história familiar, seus interesses em leitura e lazer, e não apenas questões voltadas a descreverem suas empresas e suas atuações nelas ${ }^{9}$.

\section{RESULTADOS DA PESQUISA}

Os resultados da pesquisa confirmam os pressupostos, observações e conclusões de Borges (2002), em trabalho semelhante junto a PME de diferentes segmentos. Primeiramente,

\footnotetext{
${ }^{7}$ FLANAGAN, John C. The critical incident technique. Psycological Bulletin, v.51, n.4, p.327-358, July 1954, apud BORGES (2002).

${ }^{8} \mathrm{Na}$ literatura sobre inteligência empresarial, segundo BORGES (2003), a informação é "um elemento que possibilita que as organizações conheçam as tendências do seu ambiente externo de negócios, visto que os sinais do ambiente externo têm força suficiente para determinar as estratégias das empresas, impondo mudanças significativas às suas atividades", e a inteligência empresarial é considerada uma atividade que favorece o processo de aprendizagem e consolidação do conhecimento organizacional. O monitoramento do ambiente externo é incentivado, através de práticas de obtenção e análise de informação sobre o mesmo, permitindo às empresas reconhecerem tendências, ameaças e oportunidades do mercado, e o desenvolvimento de respostas apropriadas. Para BORGES (2003), toda a literatura procurar persuadir os empresários a institucionalizarem atividades de inteligência empresarial como uma função organizacional importante, sendo a informação um fator-chave que possibilita às empresas compreenderam as "mensagens" do mercado e criarem condições de responder a esse mercado com produtos e serviços inovadores.

${ }^{9}$ FILLON, L. J. Vision et relations: clefs du success de l'entrepreneur. Montreal: Les Editions de l'entrepreneur, 1991, apud BORGES (2003).
} 
os consultores dedicam especial atenção aos contatos com clientes, parceiros, movimentos associativos e participação em eventos, ou seja, contatos que extrapolam as pessoas da própria empresa (colegas de trabalho). Além disso, apresentam hábitos de leituras variados, não somente de sua área de negócios. A observação das condutas dos consultores mostra quais são os domínios (contextos, grupos, eventos) pelos quais eles transitam, permitindo uma melhor compreensão das relações que estabelecem e como as estabelecem. Portanto, de acordo com estes resultados, e com base na Biologia do Conhecer e o trabalho de Borges (2002), a afirmação de que é mais importante compreender as condutas dos profissionais do que procurar saber qual informação é necessária para eles é corroborada neste trabalho realizado junto aos consultores empresariais.

Continuando, os consultores também afirmaram nas entrevistas que não possuem uma infra-estrutura ou atividade profissional especializada, em suas empresas, para o trato da informação, tal como é discutida na literatura e nos estudos sobre a gestão da informação e inteligência empresarial. Eles têm consciência de que precisam estar "informados" a respeito de seus negócios e do ambiente em que atuam, mas aplicam-se muito mais no estabelecimento de contatos, negociações, participação de eventos da área de atuação e atualização de leituras diversas para este propósito. Estes resultados condizem com a afirmação de Borges (2003):

Assim, confirma-se o que diz a literatura sobre inteligência empresarial: durante todo o tempo, as pessoas, nas organizações, monitoram o ambiente de negócios... e os empresários aplicam-se consideravelmente em negociações e no estabelecimento de contatos. (BORGES, 2003)

O fato dos consultores entrevistados não possuírem uma infra-estrutura especializada para a busca, registro ou disseminação de dados sobre o ambiente em que atuam não faz com que suas empresas sejam de pouco sucesso, ou que enfrentem dificuldades no mercado. Estes consultores já atuam no mercado há muitos anos, têm uma carteira de clientes sólida e afirmam que estão com projetos de expansão de seus negócios. O que prevalece é muito mais o estabelecimento de relações (pessoais) e sua manutenção com vistas às necessidades de suas empresas do que, propriamente, idéias de utilizarem uma fonte de informação documental, impressa ou eletrônica, por exemplo. Cada consultor desenvolve sua própria rede de relações, o que acaba propiciando "condutas diferenciadas" entre eles, mesmo atuando em um mesmo segmento (o de consultoria) e em um mesmo mercado (Belo Horizonte/MG). Este aspecto também foi destacado por Borges (2003), baseado em Maturana (1997):

Cada indivíduo tem histórias diferentes porque interage diferentemente com o meio, criando comportamentos específicos em cada domínio do qual faz parte. (BORGES, 2003, citando MATURANA, 1997) 
A informação, tal como é compreendida no âmbito da gestão da informação e da inteligência empresarial, não é o fator determinante e que possibilita as melhores condições de sobrevivência às empresas dos consultores. Apesar de concordarem que precisam da informação no dia-a-dia para uma boa condução de seus negócios, consideram que as melhores maneiras de monitorarem o ambiente de negócios acontecem através de suas redes de relações e interações com pessoas, suas leituras, e o próprio dia-a-dia de sua atividade, consideradas mais importantes do que um trabalho sistematizado de busca de informação. Aliás, este item não foi considerado pelos consultores como algo essencial às suas atividades, e sua ausência não acarreta prejuízos ou dificuldades no trabalho de consultoria que realizam, segundo eles. Vale ressaltar, ainda, que estes consultores são profissionais com experiência na área de gestão de empresas e, apesar de não serem especialistas em sistemas de informação, se consideram capazes de identificarem e avaliarem a necessidade ou não de implementação de sistemas de informação estruturados em suas empresas.

Por último, no bloco denominado "incidente crítico", foi solicitado aos consultores que descrevessem uma situação na qual um evento ocorrido nos seus ambientes de negócios os tenham influenciado a tomar uma decisão importante para suas empresas. Não foi especificado se este evento deveria ter ocorrido no ambiente "interno" ou "externo" da empresa. Nas três entrevistas, o evento citado ocorreu na relação entre o consultor e seu cliente. Ou seja, apesar do cliente estar "fora" da empresa, sua relação com cada consultor ocorreu no nível da interatividade, não sendo, portanto, um evento totalmente "externo" à realidade do dia-a-dia de cada consultor. Este fato demonstra que, no processo de tomada de decisão utilizado pelos consultores, foi adotado o conceito das "redes de relações e interações" considerado pela Biologia do Conhecer, pois eles se utilizaram dos contatos profissionais com os clientes para a tomada de decisão.

\section{CONSIDERAÇÕES FINAIS}

As entrevistas realizadas com os consultores vieram confirmar os resultados apontados no estudo feito por Borges (2002), tendo como base de trabalho e análise a abordagem da Biologia do Conhecer. Em primeiro lugar, pôde-se verificar que, mesmo tendo sido aplicado um mesmo roteiro aos três consultores, cada um respondeu, de maneira única, sobre os aspectos relativos ao seu negócio, embora ambos atuem no mesmo segmento de mercado, gerenciem negócios de pequeno e médio porte, e estejam situados na mesma cidade. A 
aceitação dessas diferentes realidades e explicações para um mesmo fenômeno, segundo Maturana (1997), caracteriza o que ele define como “objetividade entre parênteses".

Se numa discussão aceitamos completamente nosso interlocutor, e não estamos com vontade de impor-lhe nossa visão, nós de facto operamos tratando o outro como se ele ou ela estivesse num domínio de realidade diferente do nosso, mas igualmente legítimo. Quando fazemos isso, aceitamos que o outro está numa posição diferente da nossa, mas não afirmamos que ele ou ela está errado ou é arbitrário. (...) Se estamos na emoção da aceitação do outro e com espírito de reflexão, encontramonos operacionalmente no caminho explicativo da objetividade entre parênteses. (MATURANA, 1997).

Portanto, a forma como cada consultor distingue o seu negócio e seu mercado de atuação (meio), e os descrevem, demonstra como o conhecer sobre algo é diversificado e dependente da história de relações e interações do entrevistado com o meio (BORGES, 2003). Neste trabalho, cada consultor respondeu sobre seu mercado de atuação e suas relações pessoais e profissionais, e cada um, com sua particularidade, confirmou as conclusões de Borges (2002) de que a observação das condutas dos consultores mostra quais são os domínios (contextos, grupos, eventos) pelos quais eles transitam, o que permitiu uma melhor compreensão das relações que eles estabelecem e como as estabelecem.

Em segundo lugar, o trabalho também confirma a necessidade de estudos mais aprofundados sobre a realidade das PME, quando o foco é o tema da inteligência empresarial. Os consultores entrevistados, apesar de não utilizarem mecanismos formais ou sistemáticos de obtenção, processamento e análise de informação, têm consciência de que precisam estar informados sobre suas empresas e mercados de atuação. Eles acreditam saber muito a respeito de seus negócios e que é mais importante estabelecerem relações e mantê-las em função das necessidades de suas empresas, do que ter uma infra-estrutura sistematizada de atividade de inteligência empresarial, como ocorre nas empresas de grande porte. Por apresentarem características e dinâmicas próprias, os estudos e modelos desenvolvidos e aplicados nas grandes empresas não devem ser considerados para as empresas de pequeno porte.

Estas conclusões vêem de encontro a um terceiro ponto, comentado anteriormente, sobre o conceito de "redes de relações e interações". Podemos verificar, através dos resultados deste trabalho, que os consultores se utilizam, na sua grande maioria, das fontes pessoais (contatos, negociações) para se manterem atualizados e para monitorarem seu ambiente de negócios. Portanto, o conhecer dos consultores acerca de suas empresas e seu ambiente de negócios não ocorre, necessariamente, pela obtenção de informação sistematizada, mas no seu cotidiano de trabalho, através de suas condutas adequadas no meio e da manutenção das redes 
de relações e interações das quais participa. Estes resultados são semelhantes aos encontrados por Borges (2002), e estão em consonância com a abordagem da Biologia do Conhecer.

Em quarto lugar, este trabalho corrobora também com as conclusões de Borges (2002) de que é possível estabelecer atividades de gestão da informação e de inteligência empresarial livres de modelos e da idéia de prescrição de informação, se considerarmos a informação sob o ponto de vista da Biologia do Conhecer. Neste sentido, o foco de estudo se daria a partir da análise de como os consultores (no caso específico deste trabalho) atuam e gerenciam seus negócios, os contatos que estabelecem e como os fazem, os domínios pelos quais transitam, as pessoas próximas a eles e como essas relações entre estas pessoas e os consultores acontecem no âmbito de suas empresas.

Por último, mostra-se importante a realização de mais trabalhos para a ampliação do campo de estudo deste tipo de abordagem (Biologia do Conhecer), como foi um dos objetivos deste - trabalhos similares em outros segmentos para comparação de resultados, por exemplo.

\section{REFERÊNCIAS}

AGUILAR, Francis J. Scanning the business environment. New York, NY: Macmillan, 1967.

BARBOSA, Ricardo Rodrigues. Monitoração ambiental: uma visão interdisciplinar. Revista de Administração, São Paulo, v.32, n.4, p. 42-53, out/dez de 1997.

BARBOSA, Ricardo Rodrigues. Inteligência Empresarial: uma avaliação de fontes de informação sobre o ambiente organizacional externo. DataGramaZero - Revista de Ciência da Informação, Belo Horizonte, v.3, n.6, dezembro de 2002.

BELKIN, Nicholas J. The cognitive viewpoint in information science. Journal of Information Science, v.16, p.11-15, 1990.

BORGES, Mônica Erichsen Nassif. A informação e o conhecimento na Biologia do Conhecer: uma abordagem cognitiva para os estudos em Inteligência Empresarial. 2002. 163f. Tese (Doutorado em Ciência da Informação) - Escola de Ciência da Informação, Universidade Federal de Minas Gerais, Belo Horizonte, 2002.

BORGES, Mônica Erichsen Nassif. A Aplicabilidade da Biologia do Conhecer no âmbito da Ciência da Informação. DataGramaZero - Revista de Ciência da Informação, Belo Horizonte, v.4, n.3, junho de 2003.

BORGES, Mônica Erichsen Nassif. Informação, Conhecimento e Cognição. Belo Horizonte: Escola de Ciência da Informação da UFMG, 2004. Notas de aula.

BROOKES, B. C. The foundation of Information Science. Journal of Information Science, v. 2, Part I, p.125-133, 1980. 
CARMO, Vadson Bastis; PONTES, Cecília C. Cunha. Sistemas de informação gerenciais para programa de qualidade total em pequenas empresas da região de Campinas. Ciência da Informação, Brasília, v.28, n.1, p.49-58, jan/abr, 1999.

CHÉR, Rogério. A gerência das PME: o que saber para administrá-las. São Paulo: Maltese, 1990.

CHIAVENATO, Idalberto. Introdução à teoria geral da administração: uma visão abrangente da moderna administração das organizações. 7. ed. rev. e atual. Rio de Janeiro: Editora Elsevier, 2003.

CHOO, Chun Wei. A Organização do Conhecimento. São Paulo: Editora SENAC São Paulo, 2003.

DONADONE, Júlio Cesar. Os hunos já chegaram: dinâmica organizacional, difusão de conceitos gerenciais e a atuação das consultorias. 2001. 123 f. Tese (Doutorado em Engenharia de Produção) - Escola Politécnica da Universidade de São Paulo, São Paulo 2001.

MAFRA, P. Frederico C. Fundamentos Metodológicos da Pesquisa de Marketing. 2000. 68 f. Monografia (Especialização lato sensu em Gestão Estratégica de Marketing) - Centro de Pós-Graduação e Pesquisas em Administração da Universidade Federal de Minas Gerais, Belo Horizonte, 2000.

MARTIN, C.J. Information management in the smaller business: the role of the top manager. International Journal of Information Management, v.9, n.3, p.187-197, sept. 1999.

MATTAR, Fauze Najib. Pesquisa de Marketing. São Paulo: Atlas, 1996.

MATURANA, Humberto. A Ontologia da realidade. Cristina Magro, Miriam Graciano, Nelson Vaz, organizadores. Belo Horizonte: Ed. UFMG, 1997.

MATURANA, Humberto, VARELLA, Francisco. El arbol del conocimiento: las bases biológicas del entendimiento humano. Santiago de Chile: Editorial Universitaria, 1984.

MICHELETTI, Camila. Ser consultor é coisa (cada vez mais) séria. Instituto Brasileiro de Consultores de Organização, 2002. Disponível em <http://www.ibco.org.br>. Acesso em 26 Fev. 2005.

OLIVEIRA, Djalma de Pinho Rebouças de. Manual de Consultoria Empresarial: conceitos, metodologia, práticas. 4. ed. São Paulo: Atlas, 2003.

OLIVEIRA, Marlene, BERTUCCI, Maria da Graça Eulálio de Souza. As Pequenas e Médias Empresas e a Gestão da Informação. In: PAIM, Isis (org.) A Gestão da Informação e do Conhecimento. Belo Horizonte: Escola da Ciência da Informação / UFMG, p.219-238, 2003.

PAIM, Isis, BARBOSA, Ricardo Rodrigues. Da Gerência de Recursos Informacionais à Gestão do Conhecimento. In: PAIM, Isis (org.) A Gestão da Informação e do Conhecimento. Belo Horizonte: Escola da Ciência da Informação / UFMG, p.7-31, 2003. 
TERRA, J.C., KRUGLiAnKAS, I. Gestão do Conhecimento em Pequenas e Médias Empresas. 2. ed. São Paulo: Negócio Editora, 2003.

VAKKARI, Perti. Library and information science: its content and scope. Advances in Librarianship: v.18, p.1-55, 1994.

\begin{abstract}
This article searches to contribute for the amplification of studies about Business Intelligence and your relation with the cognitive approach of the Biology of Knowledge, from the comment of small and medium size advertising companies, using of the theoretical referential of the cognitive approach of the Biology of Knowledge, of Maturana, used in the studies made for Borges in its doctor thesis of.
\end{abstract}

KEYWORDS: Business Intelligence. Information. Knowledge. Small and Middle-sized Business. Business Consulting. Biology of Knowledge.

Originais recebidos em 05/04/2006. 